\title{
Knowledge, provision of information and barriers to high quality medication abortion provision by pharmacists in Uttar Pradesh, India
}

Nadia Diamond-Smith ${ }^{1 *}$ (D) Joanna Percher ${ }^{2}$, Malvika Saxena ${ }^{3}$, Pravesh Dwivedi ${ }^{4}$ and Aradhana Srivastava $^{3}$

\begin{abstract}
Background: The use of medication abortion is increasing rapidly in India, the majority of which is purchased through pharmacies. More information is needed about the quality of services provided by pharmacist about medication abortion, especially barriers to providing high quality information. The goal of this study was to explore the quality of pharmacist medication abortion provision using mixed methods to inform the developed of an intervention for this population.

Methods: Data was collected via convenience sampling using three methods: a quantitative survey of pharmacists $(N=283)$, mystery clients $(N=111)$, and in-depth qualitative interviews with pharmacist $(N=11)$. Quality indictors from the quantitative data from surveys and mystery clients were compared. Qualitative interviews were used to elucidate reasons behind findings from the quantitative survey.

Results: Quality of information provided to client purchasing medication abortion was low, especially related to timing and dosing of misoprostol (18\% of pharmacists knew correct timing) and side effects (31\% not telling any information on side effects). Mystery clients reported lower quality (less correct information) than pharmacists reported about their own behaviors. Qualitative interviews suggested that many barriers exist for pharmacists, including perceptions about what information clients can understand and desire, and also lack of comfort giving certain information to certain types of clients (young women).

Conclusions: It is essential to improve the quality of information given to client purchasing medication abortion from pharmacists. Our findings highlight specific gaps in knowledge and reasons for poor quality information. Differences in guidelines available at that time from the Indian Government, World Health Organization, and the medication abortion boxes may lead to confusion amongst pharmacists and potentially clients. Interventions need to improve both knowledge about medication abortion and also biases in the provision of care.
\end{abstract}

Keywords: Medication abortion, India, Quality of care, Mixed-methods

\footnotetext{
* Correspondence: nadia.diamond-smith@ucsf.edu

${ }^{1}$ Department of Epidemiology and Biostatistics and Institute for Global

Health Sciences, University of California, San Francisco, 550 16th Street, 3rd

Floor, San Francisco, CA 94158, USA

Full list of author information is available at the end of the article
}

(c) The Author(s). 2019 Open Access This article is distributed under the terms of the Creative Commons Attribution 4.0 International License (http://creativecommons.org/licenses/by/4.0/), which permits unrestricted use, distribution, and reproduction in any medium, provided you give appropriate credit to the original author(s) and the source, provide a link to the Creative Commons license, and indicate if changes were made. The Creative Commons Public Domain Dedication waiver (http://creativecommons.org/publicdomain/zero/1.0/) applies to the data made available in this article, unless otherwise stated. 


\section{Background}

Although abortion was legalized in India through the Medical Termination of Pregnancy (MTP) act in 1971, access to and knowledge of safe abortion services in public clinics remains limited [1-6]. While the MTP act requires a medical prescription to obtain medication abortion (MA) drugs at a service delivery point (hospital, clinic or pharmacy), many clients go directly to pharmacies, and pharmacists and/or pharmacy workers become their first point of care [2, 7-12]. It is currently estimated that $73 \%$ of the 15.6 million annual abortions in India are induced through MA outside of facilities, with an estimated $87 \%$ of these abortions through combination packs in which mifepristone and misoprostol are packaged together [13]. Thus, pharmacy workers are often the primary means of communication about how to take MA, what to expect, and when to seek care, to clients purchasing MA [2, 7, 8, 11].

Medication abortion using mifepristone and misoprostol has been shown to be safe and effective when used appropriately, both in and out of the clinic setting [14, 15]. While $14 \%$ of the 56 million abortions globally are classified as "least safe," done by untrained providers with dangerous methods, increasing self-use of MA is credited with helping drive down abortion-related morbidity and mortality [16-18]. Much out-of-facility use is in places where abortion is legally restricted but misoprostol is available due to its registration for other health concerns, often gastric ulcers [19]. In India, though abortion is legal, barriers to clinic-based care and the ease and relative low cost of accessing out-of-facility MA in many states has spurred its high use. While MA is safe, individuals taking the medication need to have sufficient information to have a satisfactory, supported experience. In Uttar Pradesh, where an estimated 3.15 million abortions take place annually, over 1 million individuals are treated for induced abortion complications at clinics [20]. Many of these are likely unnecessary interventions because individuals did not know how to differentiate between normal progress of MA versus a complication necessitating additional care. Furthermore, treatment for these perceived complications often use dilation and curettage, an invasive and outdated procedure, used at a higher rate in Uttar Pradesh than in other Indian states studied by Guttmacher in 2015 [21].

The reliance on pharmacies for the provision of MA in India has been known for some time, but it is less well studied. The extant research points to low quality of knowledge on MA among pharmacists [2, 7, 8, 10-12]. In a 2015 study in Madhya Pradesh, only 35\% of pharmacists provided correct information on MA regimens (including dosage and timing), and $28 \%$ correctly advised clients on where to go should complications arise [8]. A study in the states of Gujarat and Jharkhand found that $23 \%$ of pharmacists interviewed gave no information to clients when selling MA, and only $15 \%$ provided information on side effects [2]. Other studies in Delhi, Bihar, and Gujarat have found similar results. Post-abortion family planning was rarely offered or discussed at the time of dispensing MA medication [12]. These findings suggest poor quality of care for MA services through pharmacies.

In order to measure the quality of MA information and care provided by pharmacists, it is essential to understand what the published MA regimens that would potentially be available to pharmacists in this setting at the time of data collection. One challenge for MA quality provision is that multiple and differing guidelines exist in India. To illustrate this, we show the World Health Organization (WHO), the Indian Handbook on Medical Methods of Abortion and the instructions from inserts in three popular MA combination packs in India (Unwanted, MMkit and TermiPill) [22, 23] (Table 1). Of note, the WHO MA guidelines are for up to 63 days gestation and the Indian Handbook on Medical Methods of Abortion has not been updated since the gestational limit for MA was extended from 49 to 63 days in the private sector. While all have the same dose and route of administration for mifepristone, it is important to note that they differ slightly in the timing between mifepristone and misoprostol, with the WHO recommending 1-2 days (24-48 h), the Indian Handbook between "day 1 and day 3", and the MA kits 1-3 days later. The Indian Handbook on Medical Methods of Abortion also differs in that it recommends only $400 \mathrm{mcg}$, or two pills, of misoprostol, rather than the $800 \mathrm{mcg}$ recommended by WHO and in the instructions in the MA kits. Route of administration of misoprostol also differs by source.

Quality of care, including knowledge, practices, and behaviors, is notoriously challenging to measure for many health services, including reproductive health services such as family planning and MA. The standard methods, including provider self-report, client exit interviews, and observations, all suffer from biases [24]. Mystery clients have been found to provide additional information about quality of care for family planning, and it has been argued that this approach is especially valuable combined with provider self-report $[24,25]$. However, few studies to date have utilized mystery clients to understand quality for MA provision through pharmacies in India (or other outlets), but are likely to provide an additional perspective on the quality of information and care provided to clients seeking MA [8, 10, 18, 26-30].

\section{Methods}

This paper aims to explore the knowledge and information given by pharmacists who sell MA, and the barriers to providing high quality information and care through mixed methods, including a survey, mystery clients, and 
Table 1 Instructions for dosage, timing, and route of administration from three sources

\begin{tabular}{|c|c|c|c|}
\hline Category & $\begin{array}{l}\text { WHO guidelines for MA use } \\
\text { up to } 63 \text { days }\end{array}$ & $\begin{array}{l}\text { Indian Handbook on Medical Methods } \\
\text { of Abortion (Ministry of Health and } \\
\text { Family Welfare, Government of India, 2016) }\end{array}$ & $\begin{array}{l}\text { Instruction inserts from three MA } \\
\text { combination pack kits } \\
\text { (Unwanted, MM kit, and TermiPill brands) }\end{array}$ \\
\hline $\begin{array}{l}\text { Timing of mifepristone } \\
\text { and misoprostol }\end{array}$ & $\begin{array}{l}\text { Day 1: mifepristone } \\
1-2 \text { days later ( } 24-48 \mathrm{~h}) \\
\text { misoprostol }\end{array}$ & $\begin{array}{l}\text { Day 1: mifepristone } \\
\text { Day 3: misoprostol }\end{array}$ & $\begin{array}{l}\text { Day 1: mifepristone } \\
1-3 \text { days later misoprostol }\end{array}$ \\
\hline Dose of mifepristone & $200 \mathrm{mg}$ & $200 \mathrm{mg}$ & $200 \mathrm{mg}$ \\
\hline $\begin{array}{l}\text { Route of mifepristone } \\
\text { administration }\end{array}$ & Oral & Oral & Oral \\
\hline Dose of misoprostol & $\begin{array}{l}400 \text { mcg ( } 2 \text { pills) if taken } \\
\text { orally up to } 7 \text { weeks } \\
800 \text { mcg ( } 4 \text { pills) if up to } \\
9 \text { weeks taken vaginally, } \\
\text { buccally, or sublingually }\end{array}$ & 400 mcg (2 pills) at same time & $800 \mathrm{mcg}$ (4 pills) at same time \\
\hline $\begin{array}{l}\text { Route of misoprostol } \\
\text { administration }\end{array}$ & $\begin{array}{l}\text { Up to } 7 \text { weeks: Vaginal, } \\
\text { buccal, sublingual or oral } \\
\text { Up to } 9 \text { weeks: Vaginal, } \\
\text { buccal, or sublingual }\end{array}$ & $\begin{array}{l}\text { Sublingual: most recommended } \\
\text { Buccal: recommended } \\
\text { Vaginal: recommended } \\
\text { Oral least recommended but still OK }\end{array}$ & Vaginal \\
\hline
\end{tabular}

Note: Since the time of data collection, some of these guidelines have been changed, however, we present the guidelines available at the time of data collection to more accurately be able to compare the knowledge and quality of information provided by pharmacists at that time to resources available to them

in-depth interviews with pharmacists. The survey was designed to obtain a larger sample of pharmacists' self reports of their knowledge and practices. Mystery clients were used to see how these self-reports translate into behaviors towards clients. Qualitative interviews were used to explore pharmacist's knowledge and barriers to providing quality care in depth.

\section{Study setting}

The study was conducted in the urban and peri-urban areas of three districts in Uttar Pradesh - Lucknow, Kanpur Nagar and Unnao. The districts were selected on the basis of an ongoing study on maternal health quality, of which this was a sub-study. In these districts are located Lucknow and Kanpur - two of the largest cities in Uttar Pradesh, with a significant urban population and a large number of pharmacies. The social marketing firm that we partnered with estimated that there were 3 , 000-4,000 pharmacies in these three districts. We therefore expected larger clientele of MA in such settings. The third district, Unnao, was selected to represent a more peri-urban population. Data was collected between November 2017-March 2018. This study received Human Subjects Approval from the Public Health Foundation of India, India and the University of California, San Francisco.

\section{Methods and data collection}

In-depth interviews were conducted with eleven pharmacists who had sold MA to clients. Pharmacists providing MA services were identified in collaboration with a social marketing firm that also supplies MA kits to pharmacists. The social marketing firm had a list of pharmacists who they had provided MA kits to, which they shared with us, allowing us to approach pharmacists who we knew were providing MA, using convenience sampling from this list. Verbal informed consent was obtained before the interview and also for recording. Notes were taken in the event the provider refused to be recorded. An information sheet with the investigators' contact details was shared with all respondents, and they were encouraged to call in case they had any doubts later on. Interviews covered pharmacists' experiences with and barriers to providing MA (Additional file 1). Interviews were conducted in Hindi by Indian research assistants and translated to English. Interviews were thematically analyzed after coding by a team of 4 researchers (all authors) with a Grounded Theory Approach using AtlasTi software [31].

We then conducted a survey with pharmacists- 176 randomly selected (using simple random sampling) from the roster of a social marketing organization, and a random sample of 119 pharmacies not on the social marketing firm's roster, from the same areas. The only criterion was that they had to be located in urban or periurban areas. The investigators then approached the pharmacy workers and interviewed upon consent. A total of 295 pharmacists were surveyed, with 283 completing the full survey. A team of six public health researchers conducted the survey, following 2 days of training. The survey was conducted in Hindi after obtaining verbal informed consent. The informed consent also included consent for mystery clients to visit the facility at some point in the next 6 months. Data was collected digitally on tablets using the Survey CTO software. The questionnaire comprised of questions to assess pharmacist knowledge and practices surrounding medication abortion, along with a few demographic questions. Each survey was about 30 min long. Confidentiality of the respondent was strictly maintained as per protocol to prevent any leakage of 
identity or information disclosed. The place and time of interview was decided by the respondent and only conducted as per their comfort. Pharmacists were also visited during non-peak times to reduce the number of potential customers they might encounter during the interview. Interview was paused if a customer arrived, and resumed when she or he had left. Any doubts that the respondent had were satisfied before commencing with the interview.

Mystery clients visited 111 of the pharmacies that were surveyed (not those on the social marketing firm's roster) about 2 months after the initial survey. Research assistants were deployed as mystery clients assuming four different profiles: a younger, unmarried woman ( $\sim 18$ years), a younger unmarried man ( 20 years), a married woman ( $\sim 28$ years $)$ and a married man $(\sim 30$ years). The research assistants were recruited from similar communities where the study took place. Mystery clients completed a three-day training with pilot testing in the field and in-depth role plays. Mystery clients approached each pharmacist by saying that they had an unplanned pregnancy, and were trained to only probe on specifics (MA itself, side effects, dose, etc.) if the pharmacist did not willingly volunteer that information. Immediately after each interaction, the mystery client filled out a standardized digital survey about their experience, which included an open-ended section for additional notes.

Descriptive statistics were calculated for survey data (pharmacist survey and mystery client survey). Pharmacist and mystery client responses are compared where possible. All survey analysis was conducted using Stata 15MP [32]. Quality was assessed in comparison to guidelines presented in Table 1.

\section{Results}

All pharmacists in the interviews were males and had either completed a diploma or degree course in pharmacy. As can be seen in Table 1, 99.3\% of the survey respondents were men, and most were graduates in something other than pharmacy (55.5\%), with about 18\% having a degree or diploma in pharmacy. While it is mandatory to have a degree in pharmacology to open a pharmacy shop, in reality the person working day-to-day behind the counter may not be trained in pharmacy. We interviewed whoever was at the pharmacy seeing clients on the day of the visit as this most accurately represented who clients would be interacting with.

\section{Pharmacist's initial interactions with clients}

Twenty-four percent of pharmacists said that none of the people they had sold MA to came with a prescription (Table 2). Very few (5.4\%) of the mystery clients were asked if they had a prescription. Only $5 \%$ of pharmacists reported that they did not determine the woman's gestational age in any way, and of those that did, the majority
Table 2 Profile of Pharmacists in the survey $(N=283)$

\begin{tabular}{ll}
\hline & $N(\%)$ \\
\hline Gender & $281(99.3)$ \\
Male & $2(0.7)$ \\
Degree & \\
M. Pharma / B. Pharma & $24(8.5)$ \\
Diploma in pharma & $28(9.9)$ \\
Post graduate-others & $35(12.4)$ \\
Graduate-others & $157(55.5)$ \\
Not a graduate & $37(13.1)$ \\
Others & $2(0.7)$ \\
Percentage of people who came to the \\
pharmacy for MA in past month with a doctor's \\
prescription
\end{tabular}

(57.4\%) did so by trusting what the woman told them, $66.7 \%$ did it based on the last menstrual period (LMP), and $24.4 \%$ based on a doctor's report. The majority $(76.6 \%)$ of mystery clients were asked their last menstrual period, and $87.4 \%$ were asked if they took a pregnancy test.

\section{Knowledge of and information sharing on MA dosing and timing}

In the depth-interviews, all pharmacists reported that they explained the same dose as in the kit and recommended by the WHO guidelines (Table 1 ). However, only $38.2 \%$ of pharmacists stated that dosage in the quantitative survey (Table 3). Five pharmacists (1.8\%) followed the India guidelines by advising only $400 \mathrm{mcg}$ misoprostol initially be taken, followed with an additional 400 mcg "if needed," with three explicitly stating to take the second dose only if bleeding does not occur after $24 \mathrm{~h}$. In the survey, $73 \%$ of pharmacists reported spacing between mifepristone and misoprostol somewhere in the range of $24-48 \mathrm{~h}$, and $7 \%$ reported that they did not know the spacing (Table 3). Just over half $(56 \%)$ of mystery clients were told a timing between the two medications of 12-24 h.

The WHO guidelines and MA kit instructions both advise for four pills, $800 \mathrm{mcg}$ total, of misoprostol to be taken together, however only $18 \%$ of pharmacists advised for the 4 misoprostol pills in the combination pack to be taken together (with another 7\% reporting that they did not know). About a third (38.5\%) of pharmacists advised 
Table 3 Medication abortion counseling: comparing pharmacist survey and Mystery Clients

\begin{tabular}{|c|c|c|}
\hline & $\begin{array}{l}\text { Pharmacist Survey } \\
N=283 \mathrm{~N}(\%)\end{array}$ & $\begin{array}{l}\text { Mystery } \\
\text { Client } \\
N=111 \\
N(\%)\end{array}$ \\
\hline \multicolumn{3}{|l|}{$\begin{array}{l}\text { Determines gestational age, } \\
\text { and if so, how? }\end{array}$} \\
\hline $\begin{array}{l}\text { Does not determine the } \\
\text { estational age }\end{array}$ & $13(4.59)$ & No info \\
\hline Trust on client saying & $155(57.41)$ & No info \\
\hline $\begin{array}{l}\text { Based on last menstrual } \\
\text { period }\end{array}$ & $180(66.67)$ & $85(76.58)$ \\
\hline $\begin{array}{l}\text { As per doctor assessment/ } \\
\text { report }\end{array}$ & $66(24.44)$ & No info \\
\hline Other & $1(0.37)$ & No info \\
\hline $\begin{array}{l}\text { Asked if she had taken a } \\
\text { pregnancy test }\end{array}$ & & $97(87.39)$ \\
\hline $\begin{array}{l}\text { Tell clients to have anywhere } \\
\text { between a } 24-48 \text { h gap between } \\
\text { mifepristone and misoprostol }\end{array}$ & $207(73.14)$ & $60(55.56)$ \\
\hline Don't know & $21(7.42)$ & No info \\
\hline $\begin{array}{l}\text { Reported taking all } 4 \text { misoprostol } \\
\text { tablets together ( } 800 \text { mcg total) }\end{array}$ & $51(18.02)$ & No info \\
\hline Don't know & $21(7.42)$ & No info \\
\hline $\begin{array}{l}\text { Reported taking misoprostol tablets } \\
\text { in two doses of } 2 \text { pills ( } 800 \text { mcg total) }\end{array}$ & $109(38.51)$ & No info \\
\hline \multicolumn{3}{|l|}{ Route to take misoprostol } \\
\hline Oral & $256(90.46)$ & 99 (89.19) \\
\hline Vaginal & $114(40.28)$ & $12(10.81)$ \\
\hline Sublingual & $20(7.1)$ & $3(2.70)$ \\
\hline Buccal & $9(3.2)$ & $3(2.70)$ \\
\hline Other & $4(1.4)$ & $0(0)$ \\
\hline Don't know/Told nothing & $11(3.9)$ & $4(3.60)$ \\
\hline \multicolumn{3}{|l|}{$\begin{array}{l}\text { Potential side effects/reactions } \\
\text { to MA told to clients }\end{array}$} \\
\hline $\begin{array}{l}\text { Does not tell MA clients about } \\
\text { possible reactions (side effects) } \\
\text { to MA }\end{array}$ & $88(31.1)$ & $15(13.51)$ \\
\hline Nausea/vomiting & $65(33.3)$ & $9(8.11)$ \\
\hline Headache & $31(15.9)$ & $1(0.90)$ \\
\hline Diarrhea & $4(2.1)$ & \\
\hline Lower abdomen pain & $72(36.92)$ & $62(55.86)$ \\
\hline Heavy bleeding & $169(86.67)$ & 43 (38.74) \\
\hline Dizziness/weakness & $37(19)$ & 29 (26.13) \\
\hline Fever & $12(6.15)$ & \\
\hline Other & $41(21)$ & $3(2.70)$ \\
\hline
\end{tabular}

the client to take the 4 pills of misoprostol in two doses of $400 \mathrm{mcg}$ each (two pills), and $7.1 \%$ advised it to be taken in 3 or four doses. In the interview data, pharmacists reported telling clients to have a 12 to $24 \mathrm{~h}$ gap between two doses of two pills of misoprostol.
I explain to them to take the big tablet with water orally after dinner, and then two of the small tablets after 24 hours gap and the remaining two tablets the next day in the same manner. (Pharmacist 10, age 30-34 years)

The majority of pharmacists told women to take the misoprostol tablets orally (90.5\%), with $40.3 \%$ and/or reporting that they tell women to take it vaginally. While vaginal administration is recommended by all three regimens, oral is only recommended until 49 days gestation in the WHO guidelines, is the "least recommended" in the India guidelines, and is not presented in the MA kit instructions. Very few reported telling women to take the misoprostol sublingually or buccally (respectively) or did not know. From the mystery client data, almost $90 \%$ were told to take the misoprostol orally, $11 \%$ vaginally, and about 3\% buccally and sublingually each.

Some pharmacists described telling clients to take MA orally because they felt that it would scare the clients and that it was an overly "complicated" method. As one pharmacist described, he felt it would be difficult for the clients to understand how to take it vaginally:

$R$ : I don't suggest inserting pills vaginally because this route may cause excessive bleeding but yes I suggest this method when the duration of pregnancy is long.

\section{I: Do you explain to clients about other options for} taking the second dose of medication?

R: Yes, I do explain how else to take the second dose. I explain them about sublingual method; tell them to keep two tablets below tongue. But sometimes when they don't understand I just ask them to take orally with water. (Pharmacist 6, age 40-44 years)

A number of pharmacists said that it would make them uncomfortable or be awkward to tell women about the vaginal method-both for them and the woman.

I don't suggest this mode of administration as it may be awkward for both of us. I don't know whether they would understand or not, I never tried to. I just ask them to take orally. (Pharmacist 4, age 40-44 years)

\section{Information about side effects}

Almost a third (31.1\%) of pharmacists in the survey reported not telling clients about side effects, and of those that did, the most commonly mentioned were bleeding (86.7\%), lower abdomen pain (36.9\%), nausea/vomiting (33.3\%) and dizziness (19\%) (Table 3). Only 13\% of the mystery clients were not told about side effects, however, 
bleeding was mentioned less frequently (38.7\%), pain more frequently (55.9\%) and nausea/vomiting less frequently $(8.1 \%)$; other side effects were mentioned at similar frequencies.

Qualitatively, pharmacists had mixed feelings about telling clients about side effects. One pharmacist clearly explained that he did not tell clients about side effects because this would frighten them and make them not want to take (or buy) the kit.

I just tell them there is no side effect as I do not want to talk more about it...If I tell them about the progression of abortion then they will not take the kit! If I tell them that the first dose kills the foetus and the subsequent doses expel the remains, they will not take the pills, as it might be scary for them. So I don't tell them anything. (Pharmacist 2, age 35-39 years)

On the other hand, many pharmacists wanted to provide information and felt strongly that clients needed more information,

For quality care clients must know about the side effects of taking MA pills because I am seeing nowadays that mostly teenagers are using it and they do not know anything about the side effects or progression of abortion like excessive bleeding, cramps etc. - (Pharmacist 7, age 40-44 years)

However, some pharmacists provided non-evidence based information about dosing/timing and side effects, for example avoiding cold foods for 3-4 days after taking MA, or taking the tablets with milk.

\section{Barriers to providing high quality care: fears, misperceptions and stigma}

When asked about barriers to providing high quality care, pharmacists cited business-related concerns. For example one pharmacist explained how he did not have the time to explain detailed information to each client, as doing so would limit the number of customers he would be able to serve:

"For me the main barrier is time constraint. I can't give more than 5 minutes to one client because I will lose 2-3 clients while dealing with one client and this is not good for my business" (Pharmacist 7, age 40-44. years).

When asked what they told women or men who came with unintended pregnancies, $52 \%$ of pharmacists said they told clients to continue with the pregnancy if she had none or only one child. In the interviews, some pharmacists felt that it was difficult to provide information to certain types of respondents, mainly unmarried women, about pregnancy or their need for MA, because they did not feel comfortable questioning them directly about these topics. Many pharmacists openly discussed this being a barrier in their caregiving. A few pharmacists clearly stated that they felt "awkward" explaining to women about how to take MA and others, such as the one below, said that they felt more comfortable talking with male clients than female:

It doesn't matter to me whether the client is a male or female, I just do my job but yes I can say that it's easy to deal with male clients as I can ask them directly. In case of female clients I have to be extra cautious and sensitive before asking any personal questions like date of last menstrual period or pregnancy test etc. as they may feel uncomfortable in sharing these details with a male. (Pharmacist 7, age 40-44 years)

One pharmacist summed up many of the barriers discussed above clearly, relating them to the overall cultural and social norms

"Frankly speaking we as a society are still... shy to talk about these problem."(Pharmacist 8, age 35-39 years)

\section{Discussion}

Information on correct MA timings, route of administration and dosage, normal progression, side effects/complications, and appropriate referral are some of the critical elements in ensuring safe medication abortion. Our study revealed that quality of knowledge about MA is mixed among pharmacists in Uttar Pradesh-supporting past evidence in India $(2,7,8,10-12$.) Similar gaps in pharmacist knowledge on MA have been identified in other settings where individuals may purchase MA over the counter, including Kenya, Mexico, and the Dominican Republic [18, 26-28]. However, knowledge levels did not translate into behaviors, as we identified clear components of MA use for which pharmacists are providing incorrect information, most especially related to misoprostol timing and dose. One explanation of this may be that providers are confused about appropriate guidelines and thus nervous about what to tell clients, leading them to provide incorrect information. A careful analysis of the regimens pharmacists describe compared to the differing guidelines provided by WHO, Indian Handbook, and MA kit instructions, highlight the complexities of interpreting the "quality" of pharmacists knowledge. For example, the recommendations differ in exactly how long to wait between the mifepristone and misoprostol, and, depending on one's interpretation of " $1-2$ days" (does this mean $24-48 \mathrm{~h}$ ?), it would be possible to advise varying gaps and 
still be within a certain interpretation of the recommendations. Given the varying recommendations in the guidelines, it may be challenging for pharmacists to know what to tell clients, and clients to know what to take and how to take it.

The mixed methods approach used in this study provides additional insights into the quality of care provided to MA clients, aside from pharmacist knowledge itself. Overall, mystery clients reported lower quality information than was self-reported by the pharmacists, similar to another study on MA that employed both a survey and mystery clients in Madhya Pradesh [8]. This suggests that there may be a gap between knowledge and practices, which could be due to time constraints when actually counseling or lack of comfort counseling about MA, potentially to specific types of clients. The pharmacists, who were all male, discussed in the in-depth interviews being uncomfortable talking to female clients, especially about using the vaginal route of administration of misoprostol. This sheds light on the survey findings that many more pharmacists recommended the oral route than guidelines would suggest. This finding that providers are giving differential information to different types of clients, in addition to a general know-do gap, adds to the existing literature and informs potential focuses for interventions. Currently, most pharmacists in India are male, as is true for most of the formal labor force in this setting where women's empowerment and formal labor force participation is low.

Addressing provider biases through interventions that help pharmacist become comfortable communicating outside of the norms of society could help reduce stigma. Another approach could be recruiting and training more female pharmacists. Additionally, engaging pharmacists who do not provide information for fear of losing business (due to lost time or fear of clients being scared) is essential; the same is true for clinicians who could also view MA as taking away business opportunities. Bringing creative approaches used in other countries to UP to incentivize pharmacists and providers, such as financial incentives for providing counseling or providing informational materials which clients can read/view on their own or even take home with them, could remedy these issues. Successful related interventions include a project in Peru involving pharmacist training, dispersal by pharmacists of "STD/HIV prevention packs" with information to clients, and the creation of a referral system to clinics for STI management [33]. Training pharmacists on MA using a harm reduction framework has also demonstrated successful abortion and quality of care outcomes [34]. While training at scale for pharmacists and pharmacy workers throughout India may be difficult to implement and sustain, there is the need for further innovation to improve the information provision and quality of care in this context. Interventions that bypass pharmacists as the provider of information, such as hotlines or other means of support, are another approach for improving the quality of information that women receive.

This study has several limitations. In-depth interviews may not be generalizable to other pharmacists even in the three districts from which data was collected. Additionally, interviews were collected about 1 year before the survey, and thus, it is possible that knowledge or practices regarding MA changed between those time periods. Quality measures were not exactly the same in the pharmacist and mystery client surveys and therefore we are not able to compare every measure. Most of the pharmacists in our sample were male, so we know do not know whether differences exist between male and female pharmacists; however, very few pharmacist in this setting are female, therefore our data is reflective of most pharmacists in this setting. Finally, since pharmacists gave consent for mystery client visits and knew a mystery client might visit, it is possible that they were behaving differently than they would have otherwise. However, there was a 2-3 month time gap between the survey and mystery client visit, and no mystery client interactions gave any indication that pharmacists were suspicious. Despite these limitations, this study has many strengths, including the mixed methods approach applied to an understudied topic of growing importance.

\section{Conclusions}

Gaps remain between knowledge and practices surrounding MA provision through pharmacies in Uttar Pradesh, India. Lack of consistency in recommendations about MA in India is potentially feeding into poor or mixed quality of information being provided to clients purchasing MA. It is critical that the multiple stakeholders involved in assuring the quality of MA provision in India come to a consensus about recommendations so pharmacists providing MA, clients (regardless of gender) purchasing MA, those taking MA, and other providers and support for individuals taking MA, can be clear on safe and effective MA regimens. MA is a relatively small share of product sales for pharmacists, therefore, innovative approaches that encourage them to learn and provide appropriate information to all clients is needed. Above and beyond the translation of knowledge into practice, it is clear that pharmacists are providing poorer quality care to female clients, due to cultural and gender norms influencing communication about sensitive issues between the sexes. This is a worrisome finding that must be addressed to ensure women are able to take MA with accurate and complete information. Despite misinformation and socio-cultural barriers, many pharmacists are trying to and want to provide appropriate information to clients purchasing MA, suggesting that there is an opportunity to improve the quality of care for MA in this setting. 


\section{Additional file}

Additional file 1: Interview with Chemist and Clinical MA Providers/ chemists. (DOCX $123 \mathrm{~kb}$ )

\section{Abbreviations}

LMP: Last menstrual period; MA: Medication Abortion; MTP: Medical Termination of Pregnancy; STD/HIV: Sexually Transmitted Diseases/Human Immunodeficiency Virus; STIs: Sexually Transmitted Infections; WHO: World Health Organization

\section{Acknowledgements}

We would like to thank the research team and the participants who gave their time to this study. We would like to thank the members of the SPARQ (Strengthening person centered access, respect and quality) at UCSF, especially Beth Philips and Dominic Montagu. Additionally, we would like to thank Jennifer Blum for reviewing and providing feedback on this manuscript.

\section{Authors' contributions}

NDS conceptualized the study, led the data analysis and manuscript writing JP: participated in manuscript writing, including introduction, participated in qualitative and quantitative data analysis, and developed Table 1. MS: participated in data collection/training, participated in qualitative data analysis and participated in manuscript writing. PD: co-led data collection and training, reviewed the manuscript. AS: in-country PI helped conceptualize the study, co-led in data collection/training, participated in qualitative data analysis and participated in manuscript writing. All authors have read and approved this manuscript.

\section{Funding}

We would like to acknowledge the generous support of the David and Lucile Packard Foundation (2015-62545). The funder had no role in the design of the study and collection, analysis, and interpretation of data and in writing the manuscript.

\section{Availability of data and materials}

The datasets used and/or analysed during the current study are available from the corresponding author on reasonable request.

\section{Ethics approval and consent to participate}

This study received Human Subjects Approval from the Public Health Foundation of India (PHFI), India and the University of California, San Francisco. Both of these institutions have formal ethical committees/review boards. All participants gave verbal informed consent, as was approved by these committees given the nature of the data collection approach and topics. Consent was documented by the research staff in the mobile data collection tool at the start of the survey.

\section{Consent for publication}

Not applicable.

\section{Competing interests}

The authors declare that they have no competing interests.

\section{Author details}

'Department of Epidemiology and Biostatistics and Institute for Global Health Sciences, University of California, San Francisco, 550 16th Street, 3rd Floor, San Francisco, CA 94158, USA. ${ }^{2}$ University of California, Berkeley, USA. ${ }^{3}$ Public Health Foundation, Gurugram, India. ${ }^{4}$ Lucknow University, Lucknow, India.

Received: 28 December 2018 Accepted: 2 July 2019

Published online: 11 July 2019

\section{References}

1. Government of India. The medical termination of pregnancy act [Act No, 34, 1971]. 1971

2. Boler T, Marston C, Corby N and Gardiner E. Medical Abortion in India: A model for the rest of the world? London: Marie Stopes International, 2009.

3. Duggal R, Ramachandran V. The abortion assessment project-India: key findings and recommendations. Reprod Health Matters. 2004 Jan; 12(sup24):122-9.
4. Banerjee SK, Andersen KL, Buchanan RM, Warvadekar J. Woman-centered research on access to safe abortion services and implications for behavioral change communication interventions: a cross-sectional study of women in Bihar and Jharkhand, India. BMC Public Health. 2012;12(1) [cited 2018 Sep 18]. Available from: http://bmcpublichealth.biomedcentral.com/articles/10.11 86/1471-2458-12-175.

5. Centre for Health and Social Justice. Reviewing two years of NRHM: citizens report. 2007. Available from: http://www.chsj.org/uploads/1/0/2/1/1021584 9/citizenreport-2007.pdf

6. Nidadavolu V, Bracken H. Abortion and sex determination: conflicting messages in information materials in a district of Rajasthan, India. Reprod Health Matters. 2006;14(27):160-71.

7. Mishra A, Yadav A, Malik S, Purwar R, Kumari S. Over the counter sale of drugs for medical abortion- Knowledge, Attitude, and Practices of pharmacists of Delhi, India. Int J Pharmacological Res. 2016:6(03):5

8. Powell-Jackson T, Acharya R, Filippi V, Ronsmans C. Delivering medical abortion at scale: a study of the retail market for medical abortion in Madhya Pradesh, India. PloS One. 2015;10(3):e0120637 Cameron S, editor.

9. Government of India. The medical termination of pregnancy rules (amendment). 2003

10. Tariq M, Chaudhury N, Kapoor A. Medical abortion drug dispensing behavior among pharmacists in India. Busan: InXXVII IUSSP International Population Conference; Busan, South Korea 2013 Aug 26; 2013.

11. Ganatra B, Manning V, Pallipamulla SP. Availability of medical abortion pills and the role of chemists: a study from Bihar and Jharkhand, India. Reprod Health Matters. 2005;13(26):65-74.

12. Visaria L, Barua A, Mistry R. Medical abortion in India: role of chemists and providers. Econ Polit Wkly. 2008:43(36):35-40.

13. Singh S, Shekhar C, Acharya R, Moore AM, Stillman M, Pradhan MR, et al. The incidence of abortion and unintended pregnancy in India. 2015 Lancet Glob Health. 2018;6(1):e111-20.

14. Ngo TD, Park MH, Shakur H, Free C. Comparative effectiveness, safety and acceptability of medical abortion at home and in a clinic: a systematic review. Bull World Health Organ. 2011:89(5):360-70.

15. Kahn JG, Becker BJ, Maclsaa L, Amory JK, Neuhaus J, Olkin I, et al. The efficacy of medical abortion: a meta-analysis. Contraception. 2000;61(1):29-40.

16. Ganatra B, Gerdts C, Rossier C, Johnson BR, Tunçalp Ö, Assifi A, et al. Global, regional, and subregional classification of abortions by safety, 2010-14: estimates from a Bayesian hierarchical model. Lancet. 2017;390(10110):2372-81.

17. Fernandez MM, Coeytaux F. Gomez Ponce de León R, Harrison DL. Assessing the global availability of misoprostol. Int J Gynecol Obstet 2009;105(2):180-6.

18. Miller S, Lehman T, Campbell M, Hemmerling A, Anderson SB, Rodriguez H, et al. Misoprostol and declining abortion-related morbidity in Santo Domingo, Dominican Republic: a temporal association. BJOG Int J Obstet Gynaecol. 2005;112(9):1291-6.

19. Sneeringer RK, Billings DL, Ganatra B, Baird TL. Roles of pharmacists in expanding access to safe and effective medical abortion in developing countries: a review of the literature. J Public Health Policy. 2012;33(2):218-29.

20. Calhoun LM, Speizer IS, Rimal R, Sripad P, Chatterjee N, Achyut P. Provider imposed restrictions to clients' access to family planning in urban Uttar Pradesh, India: a mixed methods study. BMC Health Serv Res. et al, 2013; 13(1) [cited 2019 Apr 5]. Available from: https://bmchealthservres. biomedcentral.com/articles/10.1186/1472-6963-13-532.

21. Singh S, Hussain R, Shekhar C, Acharya R, Moore AM, Stillman M, et al. Abortion and unintended pregnancy in six Indian states. New York: Guttmacher Institute; 2018. p. 32

22. World Health Organization, editor. Clinical practice handbook for safe abortion, vol. 64. Geneva: World Health Organization; 2014.

23. Ministry of Health \& Family Welfare, Government of India. Handbook on Medical Methods of Abortion to Expand Access to New Technologies for Safe Abortion. 2016. [cited 2018 Dec 20]. Available from: http://www. nrhmtn.gov.in/modules/MMA_Handbook.pdf

24. Tumlinson K, Speizer IS, Curtis SL, Pence BW. Accuracy of standard measures of family planning service quality: findings from the simulated client method. Stud Fam Plan. 2014;45(4):443-70.

25. Diamond-Smith N, Treleaven E, Omoluabi E and Liu J. Comparing simulated client experiences with phone survey self-reports for measuring the quality of family planning counseling: The case of depot medroxyprogesterone 
acetate - subcutaneous (DMPA-SC) in Nigeria. Gates Open Res. 2019;3:1092. (https://doi.org/10.12688/gatesopenres.12935.1).

26. Lara D, García SG, Wilson KS, Paz F. How often and under which circumstances do Mexican pharmacy vendors recommend misoprostol to induce an abortion? Int Perspect Sex Reprod Health. 2011;37(02):075-83.

27. Reiss K, Footman K, Akora V, Liambila W, Ngo TD. Pharmacy workers' knowledge and provision of medication for termination of pregnancy in Kenya. J Fam Plann Reprod Health Care. 2016;42(3):208-12.

28. Lara D, Abuabara K, Grossman D, Díaz-Olavarrieta C. Pharmacy provision of medical abortifacients in a Latin American city. Contraception. 2006; 74(5):394-9.

29. Ngo TD, Park MH, Nguyen TH. Pharmacy workers' knowledge and provision of abortifacients in Ho Chi Minh City, Vietnam. Int J Gynecol Obstet. 2012 May; 117(2):187-8.

30. Huda FA, Ngo TD, Ahmed A, Alam A, Reichenbach L. Availability and provision of misoprostol and other medicines for menstrual regulation among pharmacies in Bangladesh via mystery client survey. Int I Gynecol Obstet. 2014 Feb;124(2):164-8.

31. Muhr T. ATLAS.ti, Version 8, Sci Softw Dev GmbH, Berlin. 2013

32. StataCorp L, others. Stata data analysis and statistical Software. Spec Ed Release, vol. 10; 2007. p. 733.

33. Garcia P, Hughes J, Carcamo C, Holmes KK. Training pharmacy workers in recognition, management, and prevention of STDs: district-randomized controlled trial. Bull World Health Organ. 2003:81(11):806-814.

34. Tamang A, Puri M, Masud S, Karki DK, Khadka D, Singh M, et al. Medical abortion can be provided safely and effectively by pharmacy workers trained within a harm reduction framework: Nepal. Contraception. 2018;97(2):137-43.

\section{Publisher's Note}

Springer Nature remains neutral with regard to jurisdictional claims in published maps and institutional affiliations.

Ready to submit your research? Choose BMC and benefit from:

- fast, convenient online submission

- thorough peer review by experienced researchers in your field

- rapid publication on acceptance

- support for research data, including large and complex data types

- gold Open Access which fosters wider collaboration and increased citations

- maximum visibility for your research: over $100 \mathrm{M}$ website views per year

At $\mathrm{BMC}$, research is always in progress.

Learn more biomedcentral.com/submissions 